It is evident from the foregoing quotation that the modern habit of "selling the climate" began early in the history of the Pacific coast.

\title{
The Livery Companies of London
}

THE mediaeval craft guild owing its origin to religion, and protected by the church, was a remarkable institution in its way, caring as it did, at least in its best days, for the well-being of its members while exacting from them a certain standard of workmanship. It is an arguable point that the worker of the Middle Ages, often engaged on creative tasks and deriving from his labor the satisfaction of his artistic instincts, was a happier man than the modern factory employee, whose work frequently consists in the continuous repetition of one monotonous operation. However that may be, there is no denying the picturesque element that attaches to the surviving guilds of London - the Livery Companies. These companies, which have long since divested themselves of their connection with their distinctive trades, and which the average person usually thinks of as organizations whose primary purpose is the providing of elegant banquets as opportunities for Guildhall speeches, are still tenacious of their municipal privileges, and in their existence perpetuate many phases of mediaeval municipal institutions.

The Society has recently acquired an attractive collection of the histories of the various Companies as well as several volumes dealing with them generally. The histories, mainly nineteenth-century works, include the Merchant Taylors, the Skinners, Drapers, Tallow-Chandlers, and other well-known Companies. So far, those of the Fishmongers, Haberdashers, Salters, and Vintners are lacking. It is aimed to complete the set.

Charles F. Heartman, at Metuchen, New Jersey, publishes a periodical most valuable to librarians, The Americana Collector. In its pages the reader explores all phases of the antique and the curious, from the letters of Carlyle to the superstitions current among the Pennsylvania Dutch. From a book on the latter comes a prescription for avoiding injuries: "Carry the right eye of a wolf fastened inside your right sleeve." 


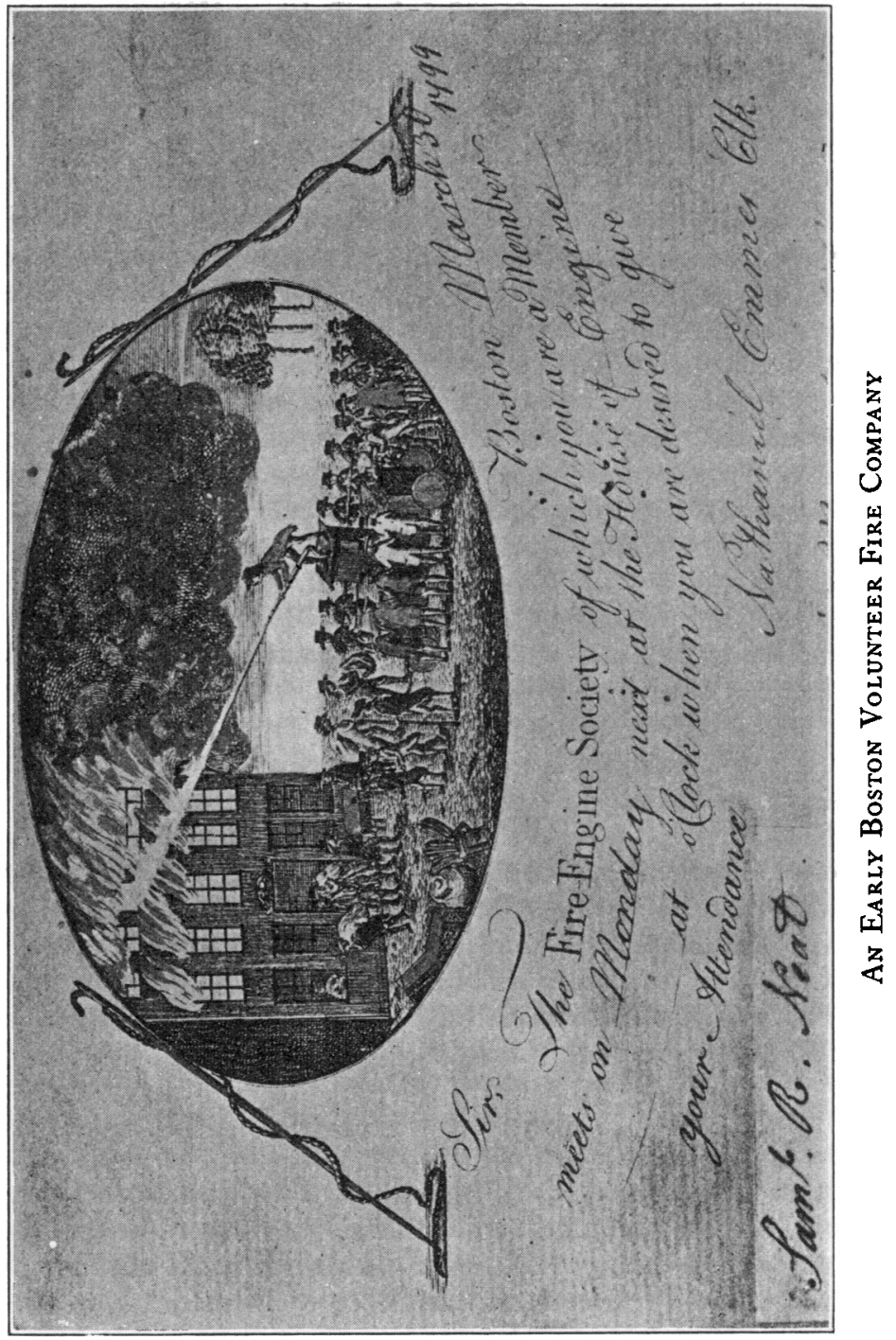

